\title{
Looking Back and Moving Forward
}

\section{The 1oth Anniversary of Religion and Gender}

\author{
Anne-Marie Korte | ORCID: 0000-0002-1738-9994 \\ Utrecht University, Utrecht, The Netherlands \\ a.j.a.c.m.korte@uu.nl \\ Nella van den Brandt | ORCID: 0000-0002-0934-5422 \\ Utrecht University, Utrecht, The Netherlands \\ nellavandenbrandt@gmail.com
}

Religion and Gender exists 10 years! Launched in 2011, Religion and Gender has established itself as the leading interdisciplinary journal for the study of gender and religion from inter- and transdisciplinary perspectives. As the journal editors, who worked hard to establish and run this journal throughout the years, we are happy and proud of having accomplished Religion and Gender's 1oth anniversary. We think this is an occasion to celebrate and pay attention to, firstly by giving many thanks to all authors who published in this journal during the past ten years. We are so grateful for their wonderful contributions! We could not have fulfilled this task, however, without the help of many of our colleagues, who acted as indispensable fellow editors, guest editors, advisers and/or peer reviewers. These colleagues, and the support they provide, have been crucial in guaranteeing the high quality and cutting edge-ness of the journal. So we are very grateful to all of them, including the members of the editorial board, for contributing to the quality and impact of the journal by gathering their networks, refereeing articles, and publishing their work.

\section{$1 \quad$ Looking Back}

The 1oth anniversary of Religion and Gender is of course also an ideal occasion for looking back, reflecting and moving forward. In this anniversary editorial, we hope to accomplish looking back and reflecting on the journal developments as well as moving forward, or at least generating openings towards new directions. Looking back necessitates first of all, of course, rethinking the jour- 
nal's founding aims and ambitions. When re-reading the 2011 mission statement of Religion and Gender formulated by the founding editors in the introduction of the journal's very first issue, there are three remarkable points to reflect upon in light of the journal's scope and aims and its subsequent development. We will attend to these three points in subsequent sections.

\subsection{In the Beginning: Theoretical Ambitions}

In the first place, the journal's scope and aims seem to have been adequately presented by both a well-thought approach to religion and gender as well as a sketch of the intricate relationships between these two subjects. Religion and Gender, one of the founding editors wrote, "explores the relation, confrontation, and intersection of gender and religion, taking into account the multiple and changing manifestations of religion in diverse social and cultural contexts. It analyses and reflects critically on gender in its interpretative and imaginative dimensions and as a fundamental principle of social ordering. It seeks to investigate gender at the intersections of feminist, sexuality, queer, masculinity and diversity studies" (Korte 2011, 1). The journal's ambition was to focus in particular on contemporary debates and topics of emerging interest from postmodern, postcolonial and post-secular perspectives.

The reasons outlined to launch the journal under the title of Religion and Gender all still seem relevant today. First of all, the title 'religion and gender' was meant to make more visible and academically challenging the research questions and aspirations engendered and promoted by feminist theology and women's studies in religion(s) of the mid-nineties. This "(re)assembling and transformative capacity of the key terms religion and gender" was considered an important heritage to build on (Korte 2011, 6). Secondly, the mission statement observed and affirmed the tendency not to follow the disciplinary divisions of theology and religious studies, but to (re)connect the study of religion to current social and political questions, moral concerns and lived spirituality (Korte 2011, 6-7). Thirdly, the text pointed at the widespread public attention paid to issues of religion and gender as markers of social conflict, cultural controversy and political contestation. The construction of gender and sexuality as a main arena or battlefield of religion(s) in our contemporary era was considered to lead to the urgency to "explore the current major challenges for the study of religion and gender, to identify the fundamental critical issues, and to address them in innovative ways and from an interdisciplinary perspective, in order to break new ground in the understanding of the complex dynamics of religion and gender in our contemporary world" (Korte 2011, 7).

It is precisely regarding the third and final reason that the relevance of our mission statement of 10 years ago seems to have further increased. We still see 
religion and gender, our two key terms, in their combination as an eye-opener, capable of opening up new debates exactly because of their destabilizing, even 'troubling' references. Both 'religion' and 'gender' are not static phenomena but are involved in ongoing and complex processes of change. This is particularly the case in the current globalizing world, where religion and gender are manifested in multiple ways and becoming increasingly complicated. The importance of this final point is also demonstrated by the responses we received to our enquiry into where Religion and Gender currently stands and what its future agenda should be, about which we will say more later.

\subsection{Open Access: Accessibility}

A second issue that needs to be discussed in light of the original mission statement of Religion and Gender concerns the reasons we have had for abandoning the initial position of publishing this journal in 'open access'. Religion and Gender was originally launched as an open access (OA) journal. For reasons outlined in detail in the 2011 introduction to the first issue, the founding editors were committed to the idea of 'direct publishing' and 'free entrance'; in their words, open access "represents and materializes our stance on the accessibility and the social relevance of this journal, its visibility, its intermediary role in current and emerging debates, and its function in warranting the author's ownership of intellectual work as much as possible" (Korte 2011, 8). At that time, open access was a newly emerging development in academic publishing. We hoped that the journal could help setting a new, ground-breaking trend, especially in the Humanities and Social Sciences. Supported with a grant from the Netherlands Organisation for Scientific Research (NWO), the journal was able to cover its publishing and running costs for the first couple of years, and the editors used this period to explore possibilities for developing a sustainable $\mathrm{OA}$ business model. However, as we reported in a subsequent editorial, "the field of Open Access publishing is complex [...] and from an international perspective developments in this field are far from uniform" (Editors 2014, 92).

In 2015, Religion and Gender became the journal of the newly established International Association for the Study of Religion and Gender (IARG), which provided us with a relevant academic home and an organisational structure. Together with IARG and our open access publisher, U-Open, we continued exploring our future publishing strategy. We have learned that for a variety of complex reasons, the field of open access publishing has not developed in the way we hoped for when launching the journal. It turned out to be very difficult to run a journal on the basis of oA principles, without sustainable alternative sources of income to cover the publishing costs. The route that many other OA journals have taken, of applying author-processing charges to replace 
income through subscription fees, has seemed to us a problematic solution, as it excludes many possible contributors who do not have access to funding covering such charges. We reached the conclusion that for the journal's long-term sustainable development, it is of key importance to work with an established academic publisher. Our first priority is, after all, publishing a high-quality interdisciplinary journal with original and innovative content that helps to enhance and transform our field of intellectual inquiry.

After conversations and negotiations with several publishers during a few years, in the first editorial of 2019, we announced that as from then on, Religion and Gender would be published by Brill, a leading international academic publisher with a strong reputation in the Humanities and Social Sciences, in collaboration with the IARG. As we wrote, "we believe that Brill's wealth of experience with high-quality academic publishing will allow the journal to further establish itself, find its way to new groups of readers and authors, and gain in academic credentials" (van Klinken and van den Brandt 2019, 2). The upcoming years, together with Brill, we will continue to follow developments in the world of academic publishing and to explore opportunities to run on an open access basis. Nevertheless, for the time being Religion and Gender operates as a subscription-based journal. We do notice, however, that the publishing world is starting to move: at the moment, due to institutional so-called Read-and-Publish agreements, authors from the Netherlands, United Kingdom, Sweden, and Austria can publish their research articles in full open access in Religion and Gender from 1 January 2020 or 2021 (see https://brill.com/ page/institutionaloa/institutional-open-access-agreements). We fiercely hope that this trend will spread further. At the same time, we remain aware of the fact that our decision to publish with Brill raises critical questions about the accessibility, dissemination and societal impact of the academic work that Religion and Gender publishes and seeks to promote.

\subsection{The Politics of Location}

The third issue we want to discuss as to reflect on the original mission statement is arguably the most critical. The 2011 original statement included the following sentence: "Albeit international in scope, the journal takes seriously that it is situated in contemporary Europe" (Korte 2011, 1). This 'contemporary Europe', so it was explained, referred both to the founding editors' own background, as well as to a position considered an important starting point to reflect on and theorize from: we envisioned a Europe based journal for religion and gender, and this was in fact placed over and against political and academic developments in the United States. Probably, our back then sole scholarly basis in the Low Lands was not coincidental to this politics of location, as we were 
thinking and speaking from a context of rapid institutional and social secularisation, with major consequences for the fields of theology and religious studies, which faced diminishment. At the same time, the study of religion and gender in disciplines like sociology, anthropology and related humanities was growing. Although many different scholars were invited to reflect on the launch of Religion and Gender, in hindsight it is clear that the network comprised at that moment mainly North-Atlantic scholars. All of this shows our preoccupation at the time with North-Atlantic relations in which the founding editors wanted to take a position.

This has changed significantly in the past ten years: the composition of the editorial staff has changed, as have the themes published by Religion and Gen$d e r$, as shown, for example, by our thematic issues on religion, gender and migration; Pussy Riot's Punk Prayer in Moscow; family law in Islamic majority countries; and Christianity and sexuality in Latin-American countries. We have gained a much broader base of authors than the original North-Atlantic scholars which formed our network at the start of Religion and Gender, and as the invited reflections published in this anniversary issue will show, we have nowadays connections with broad and different networks. It is interesting to note that today scholars with a theological background and/or appointment stand next to scholars from religious studies and gender studies, and that local differences, including those within Europe, have become much more visible and have replaced the 'based in Europe' perspective. This claim also surfaces repeatedly in the responses we received to our invitation to rethink the future agenda of the study of religion and gender - to which we turn to below - namely an emphasis on the need for (g)local positionings conceptualised in geographical perspectives, against the 'self-proclaimed universality' of Western epistemologies.

\section{Looking Forward}

With our first issue published in 2011, we organised what we considered a 'grand opening' of Religion and Gender with a discussion of the most critical issues for the study of religion and gender at that moment. In the founding issue, we wanted to provide the state of the art of the study of religion and gender, to identify the most salient points of contemporary debate, and to present the challenges facing this field of studies. Margaret D. Kamitsuka, Paul Reid-Bowen, Claudia Schippert, B. Scherer, and Adriaan van Klinken have contributed articles that fulfilled the task of setting the stage for the years to come. They encouraged to further think critically about ongoing feminist engagements, 
new materialism and the speculative turn, queer studies and its intersections with postcolonial studies, the 'tradition versus modernity' debate, and the concept and discursive framework of patriarchy in relation to agency and gender. Many subsequent special issues and individual articles furthered critical thinking about these topics, suggested new approaches and themes, and raised new questions and topics.

\subsection{Rethink We Must!}

Now, 10 years later, we want to rethink the main stakes of Religion and Gender, and again we hoped to receive input from a number of colleagues. This time we did not primarily use the network of our editorial board, but instead predominantly reached out to colleagues about whose work we got to know during the past ten years due to new and diversified networks. We are so enormously pleased that we have received in response to our invitation 15 reflections! We invited these colleagues to shed light on what they think is - or should becrucial in discussions about religion and gender for the next 10 years, of course starting from their own expertise and experience. In what follows we introduce the reflections written by Sharon A. Bong, sJ Crasnow, Karina Felitti, Veena Howard, Courtney Ann Irby, Andrea R. Jain, AnaLouisa Keating, Abeera Khan, Olga Sasunkevich, Sanober Umar, Kathrine van den Bogert, Margaretha A. van Es, Adriaan van Klinken, Eline Vuola and Tanya Zion-Waldoks. We are truly grateful for the time and efforts they put into providing us with their suggestions and ideas for how to move forward in the study of religion and gender. A warm thanks to all for their inspiring essays!

A few striking characteristics of these essays include the large variety regarding the locations from which they emerge as well as the locations on which they reflect - Latin America, Malaysia, Canada, India, the Nordic and Eastern Europe, Israel, the USA, the UK and the Netherlands-, the inclusion of both junior and senior academic researchers, a shared critical involvement with and connection to issues of religion and gender, and the emergence of many suggestions about how to move forward. In the founding issue, Claudia Schippert urged us to become more 'un-disciplined' (2011, 69), not only regarding theology and religious studies, but also regarding gender studies. This call for undisciplinedness seems implicitly underlined by a large part of the 15 reflections. It is explicitly embraced by Courtney Ann Irby, who observes apparent chasms between early feminist sociology of religion and the contemporary sociology of gender, as well as between studies of religion and gender and studies of religion and sexuality, resulting in 'bifurcated conversations'. The 15 reflections together call for un-disciplining in terms of the need for increased interdisciplinarity as well as globality and interculturality in the study of religion and 
gender, but un-disciplinedness also emerges from a sharp awareness of the contemporary conflicts and controversies in which we find ourselves, including anti-gender and anti-trans ideologies, which demand new types of questions and approaches.

\subsection{Spring 2021: (G)local Disasters}

A final but important observation needs to be made here. The invitation to contribute to this anniversary issue was send to 30 colleagues situated around the globe in Spring 2021. While we received many positive replies, as March, April, May and June progressed, many contributors experienced difficulties to deliver on their promise to provide us with their essays on time, and requested a delay of the agreed upon deadline, or withdrew from their commitment. Various authors and/or their family members and friends, nearby and far away, got infected with Covid-19, and this took (temporarily) a lot or all of their time and energies. The recent Covid-19 developments in India, with their dire consequences, poured into our mailbox via the concerns and fears of some of the contributors. Spring 2021 was also a period of escalated conflict in Israel/Palestine, which for some contributors led to concerns about the safety of themselves as well as their loved ones. Many of these colleagues still managed to submit their essays, but some were forced to withdraw their contribution. We are pleased with all contributions, of course, but are nonetheless all the more grateful for those that were written in the midst of difficulties, fears and sorrow. We are humbled, and hardly know how to express our thanks and gratitude.

\section{3}

Moving Forward

In our invitation, we formulated five leading questions, which the authors could potentially relate to in their reflections, and which many indeed did. Let us now introduce and honour the 15 essays by exploring how they provided us with answers to the five main questions.

- How does the actual configuration of religion, in its various guises across the globe, question and challenge the basic concepts (and presuppositions) in the study of religion and gender?

Religion, starting from a critical perspective on gender, should not only be approached on the basis of Western and/or Christian categories and definitions, a number of the reflections emphasises. As Elina Vuola puts it, " $[\mathrm{m}]$ ost nowadays standard ways of theorizing in the study of religion and gender have 
been developed not only in Anglophone but also primarily Christian contexts." This critical awareness is all the more crucial, of course, when studying nonChristian traditions, whether located in or outside of so-called Western countries, such as Islam. According to Sanober Umar, "[c]artographies of religion in academic literature have yet to earnestly confront, or "decolonize," the contentious canonization of certain areas of the world as representative of major and pluralistic faiths like Islam." In a similar vein, Abeera Khan emphasises that "religion and gender are both sites of contestation for Western anxieties that are always already racial in their nature." In other words, according to these contributors, 'religion' cannot be separated from its situated origins, and importantly, the colonial and racial histories of its enunciation.

A reflection on what is considered to be, or not to be, 'religion' is of importance when studying religion and gender for various reasons. Instead of only paying attention to insitutionalized religious traditions and communities, what are considered non-religion and alternative spiritualities need to be explored further as well, including what could be called dissident forms of religious ways of life. Across Latin America, spirituality gains visibility and expands its influence in society and politics. This situation, Karina Felitti argues, "calls for novel research that addresses the implications of the emergence and development of feminist spirituality in domains such as sexual and reproductive rights and health care and health management." Also comparative studies of religious traditions and communities is called for in order to explore gender relations. As Veena Howard puts it, "[t]here is a need to employ cross-disciplinary approaches that negotiate multiple languages, perspectives, and periods from India's religious traditions and experiences, which often have been overlooked."

While exploring religion and gender beyond Christianity is considered crucial, Kathrine van den Bogert raises the question whether it is the case that in studies of Muslim individuals and groups too often everything that Muslims do is understood to be related to 'religion', in this case Islam. She wonders: 'The post-secular turn in feminist research has made us aware that public space and women's agency is not automatically secular; but is it automatically religious when Muslim bodies enter that space? Is art always 'religious' when it is performed by Muslim bodies?" Karina Felitti foregrounds the Covid-19 pandemic as forcing us to think about and develop new perspectives in the study of religion. The importance of digital communication in 2020 and 2021 during the quarantines imposed by the coviD-19 pandemic leads her to observe "that the articulation and expression of religion in cyberspace is a key topic for the upcoming years. Digital ethnography that considers online and offline interactions in continuity, allows the study of the rituals, political interventions and digital activities of religious and spiritual communities in cyberspace." 
Tanya Zion-Waldoks urges us to take use "locally-centred approaches, particularly one focused on previously overlooked cases or marginalized lives" as a starting point for theorizing about religion, as well as gender and feminism. Zion-Waldoks sees this ideally taking place in combination with a comparative approach examining different groups separately and in conversation with each other, as this sharpens "the need for more reflexivity about the connective tissue between them; and for using the differences between them to challenge previous conceptualizations and shed light on theoretical blind spots."

\section{- How does the renewed and new theorizing of critical studies of race, post- coloniality, and decoloniality question and challenge the basic concepts (and presuppositions) in the study of religion and gender?}

Current debates about decolonising and deracializing academic knowledge production are at the forefront of the reflections on the future of religion and gender. Religion and Gender, Adriaan van Klinken argues, "can only be a truly international — that is, global—journal, and a viable, critical field of studies, when it interrogates and helps to transform the 'geopolitics of knowledge' in academia and beyond." Van Klinken urges us "to interrogate the 'selfproclaimed universality' of Western epistemologies, and to acknowledge the existence and validity of multiple ways of knowing the world." Sanobar Umar argues for becoming aware in the study of religion and gender of the connections between constructions of religion and race. Umar states that "in the context of racialization and religion in the West, Islamophobia is not merely religious bigotry but an act of ascribing dehumanizing and homogenizing prescriptions to racialize Muslims. These are important perspectives to our understanding of racialization and its intersection with religion beyond physiological and phenotypical constructions of race, and how gender becomes a performative marker of racial biopolitics." Taking the work of twentieth- and twentyfirst-century US women of colors as a starting point, AnaLouise Keating considers M. Jacqui Alexander and Gloria Anzaldúa as providing us with "decolonial visions and invitations that expand conventional Kantian metaphysical frameworks." Keating sees in the writings of Alexander and Anzaldúa a 'politics of spirit', which represents "a Spirit-infused approach to activist work that draws on the Sacred, as well as spirits, ancestors, beyond-human forces, divinities, and/or subtle energies, to effect progressive social change at both personal and collective levels."

For Courtney Ann Irby Religion and Gender represents itself a special space for the project of moving interdisciplinary discussions further. Her take on this could perhaps be extended to rethinking religion and gender from the perspec- 
tive of critical studies of race, postcoloniality and decoloniality: "an important venue where we can create a small world network. [...] Scholars of intellectual, scientific, and artistic innovation have argued that a balance of familiarity and diversity is required for innovation." Irby continues that "[a]s a journal not bounded to a discipline but, rather, with the goal of serving as a forum on religion and gender, Religion \& Gender holds this potential." This special position of Religion and Gender is also commented upon by Tanya Zion-Waldok: "I believe it would be productive to pay more attention to how various cases work as nodes in a network, or players on a field: how do different—but linked—social forces and movements interact with one another? We rarely examine how different feminist struggles, or struggles surrounding gender politics, shape one another."

\section{- What are the implications of queer and trans theory for the study of religion and gender?}

Knowledge of queer and trans theory is important for the study of religion and gender. However, from a number of reflections the additional insight emerges that it is crucial to theorize queerness, transness, gender and religion from the concrete spaces or locations in which the researcher and/or research informants or topics are situated and the analysis is conducted. Sharon A. Bong formulates the precarity of her position as an Asian based scholar working at the intersection of genders, sexualities and religions in South-Asia: "an oddity in religious studies and gender studies." She continues that "[i]n that regard, doing queer or doing gender has a parallelism with doing religions in making visible white privilege, male privilege and class privilege that are embedded in critical discourses." Karina Felitti similarly emphasises that "queer and trans studies in Latin America claim their distances from the academic production of the Global North. In some cases this also includes the use of "cuir" instead of queer, the Spanish spelling of that word." Abeera Khan suggests to forge innovative connections, both politically and analytically, between discussions about religion, gender and race through exploring the violent essentialisms inherent in transphobia and Islamophobia in Western European contexts. As she puts it: "Even though the articulation of the threat posed by Muslims often uses the language of queer- and transphobia, the articulators of these discourses tend to have much in common with the repressive politics that the objects of their anxieties are accused of possessing." Olga Sasunkevich emphasises the position of Eastern Europe as inhabiting an ambivalent space between what is considered to be the "non-European Islamic East" and the "European secular West". Sasunkevich argues that "acts of resistance implemented through 
inhibiting the norms of religion, exhibiting that one can be both a feminist and a believer, a queer person and a devoted Muslim or Christian, is an important subject of investigation both scholarly and politically." Andrea R. Jain suggests to connect queer and trans theory to, or merge with, planetary ecology and animal ethics, which she considers crucial in this era of pandemics. "What is the role of religion", Jain asks, "in conferring the status of free individuals and good citizens on "hard workers," while constituting others-from non-human animals, colonized subjects, and "illegal aliens" to scroungers and felons-as beings absent of morals and worthy of less? What religious logics of animality undergird debates regarding gender, sex, species, and environment?"

\section{- Why are the fields of embodiment, sexuality and gender the battlefields par excellence where the tensions between religion(s) and secularism are man- ifested in contemporary societies?}

The question why embodiment, sexuality and gender are 'battlefields par excellence' in current societal conflicts, and how this relates to tensions which could be analysed in post-secular and postcolonial terms, is not reflected upon explicitly in most contributions that we have received. But if we look at the themes that are presented in these reflections we can see in contexts as different as the USA, Latin America and Europe critical responses towards anti-gender and anti-trans movements from the perspective of religion and gender, which makes these conservative political movements some of the most salient to analyse in this light at the moment. As also Eline Vuola observes, "[i]n different regions, including Europe, and religious traditions, social, legal and political changes are growingly legitimized by patriarchal interpretations of religion. These have direct influence on ordinary women and men, with a particular influence on sexual minorities." These changes and movements demand an increasing awareness of the need for political and intersectional analyses. Discussing anti-transgender movements in the USA in the case of legislation regarding sports, sJ Crasnow remarks: "Framing trans rights as about fairness for non-trans girls and women in the face of "biological" difference relies on a legacy of racist, sexist, heterosexist, and cissexist science and ignores the history of trans athletes who have competed without incident." Arguments based on such a framing blend "secular" scientific claims and theological ones, as such, according to Crasnow, "weaponizing "biology" via the rhetoric of "gender ideology." Olga Sasunkevich observes that "Orthodox, Protestant, Roman and Greek Catholic Churches in Ukraine form an unusual alliance in promoting anti-gender rhetoric." Therefore, Sasunkevich sees a need for a more systematic bottom-up approach to religion, sexuality and gender in Eastern Europe. The 
ethnographic take on religion through the eyes of feminist and LGBTI+ actors across Eastern Europe would complement "the established tradition to analyze the role of religion in promoting and consolidating anti-gender and homophobic politics in the region."

\section{- How do we relate actual scholarly-analytical approaches to the study of religion and gender with the political origins and edges of feminist, queer, postcolonial and critical race theories?}

Also this question is not reflected upon explicitly very often, but again the contributions all demonstrate an awareness of the crucial relation between actual scholarly-analytical approaches and the political edges of feminist, queer, postcolonial and critical race theory. Sharon A. Bong, for instance, pleas for taking up a scholarly activist position in the deliberate choices for the underprivileged communities she works with: when inductively theorising and theologising from the lived realities of some of the most disenfranchised communities (including migrants and refugees in the time of the Covid-19 pandemic), one takes on the 'posture of witnessing' the trauma, healing and spaces inbetween and betwixt. Abeera Khan is similarly explicit in her claim that a critical analysis of transphobia and Islamophobia is not only an analytical endeavour. Instead, it is crucial in setting the terrain for and envisioning "seemingly unlikely alliances." AnaLouise Keating wonders how we can learn from US women of colors' feminism. This is not solely an analytical question, but it is political and spiritual too: "[W] estern thought's secularism and over-emphasis on epistemology (thanks at least in part to Immanuel Kant) has lead us to ignore or downplay metaphysical investigations. By so doing, we unnecessarily limit ourselves and our work."

Margaretha A. van Es interestingly turns the question about the politics of feminist and queer studies on its head by pointing at a perhaps unintended consequence of a dominant focus on women and queers: the relative lack of critical perspectives on cisgender, heterosexual masculinity and men. According to van Es, "[ $\mathrm{t}]$ his way, men - and especially cisgender, heterosexual menseem to remain in the proverbial 'eye of the hurricane'. [...] [W]hile the experiences of cisgender, heterosexual men are the unmarked norm from which the experiences of women and queer people supposedly deviate (and often are measured against), these men's experiences are seldom explicitly analyzed from a gender perspective, and they are seldom invited to reflect on their experiences as men either." Elina Vuola presents in reaction to this question a very practical idea for Religion and Gender: "How could critical, scientific research on religion and gender have a greater impact in our societies, when important 
societal issues are framed in terms of both religion and gender? One possibility would be thinking of a section in the journal, which would include more policy and politics relevant discussions on the basis of research."

Finally, Adriaan van Klinken, one of the founding editors of this journal, calls for paying more attention to the potential creative and imaginative aspects of the study of religion and gender. In the original mission statement of the 2011 introduction to the journal's first issue, this was formulated as such: Religion and Gender "analyses and reflects critically on gender in its interpretative and imaginative dimensions and as a fundamental principle of social ordering" (Korte 2011, 1). This raises for van Klinken the question as to whether Religion and Gender emphasised during the past ten years the interpretative dimension of the (interconnection between) gender and religion much more than the imaginative dimensions? The journal's primary commitment proves to be, in practice, to scholarly analysis more than to politically engaged and socially transformative scholarship. Van Klinken thus wonders "whether greater attention to gender and religion, not only as interpretative but also as imaginative categories can help to address and overcome this conundrum in a constructive manner."

We invite you to read this anniversary issue, and hope you will enjoy its richness in terms of the diversity of issues discussed and the suggestions for new research directions. The issue commences with two independent academic articles. After these articles, the reader will find the 15 reflections introduced and reflected upon above. Finally, the issue concludes with two book reviews.

The first article was written by Iuliana Cindrea-Nagy, and is entitled '“... as the young girl told them so": Women and Old Calendarism in Interwar Romania.' The article provides a unique insight into the history of Old Calendarist communities in Romania by presenting new sources relating to the neglected history of the practice of incarceration in Orthodox monasteries in the region. Focusing on the role and experiences of women and young girls, Cindrea-Nagy shows how they were crucial in terms of membership and the preservation of Old Calendarist ideas. In contrast to the extremely negative dominant representation of these women in the contemporary Orthodox Church, police reports and popular press, the sources analysed by Cindrea-Nagy provide us with knowledge about these women's private life, personality and motivation. The article is an important and beautiful illustration of what we gain by delving into forgotten and/or neglected histories of marginalised communities. 
The second article, "Christianity, Coloniality, and Social Change: Everyday Ethics of the Two YwCAs of South Africa" was written by Eleanor Tiplady Higgs. The article explores the diverging developments of the since 1931 two separate Young Women's Christian Associations (YwCA s) in South Africa. Tiplady Higgs demonstrates how each has responded differently to its origins in British coloniality and missionary, evangelical-Protestant Christianity, resulting in diverging ethical responses to coloniality, racism and apartheid. Based on historical and comparative research, the author argues that the YwCAs did not arrive at similar understandings of how they should respond to their socio-political context. The history of the YwCAs in South Africa thus demonstrates the complex interaction of institutional Christian identity with other personal and collective commitments, namely race and nation. The article can perhaps be read as an answer to the call made in some of the reflections for thinking more and in-depth about the connections between religion and race.

After these two articles and the 15 reflections, this anniversary issue concludes with two book reviews, written by Seán Henry and Eline Huygens.

To conclude this 1oth anniversary editorial, we again warmly thank all the authors who have contributed to this issue! The issue in its entirety, and the 15 reflections specifically, provide us with valuable insights into how religion and gender are thought through and analysed in various locations around the globe. We can only underline all the suggestions for new directions to take in the future study of religion and gender. We simultaneously believe that we also need to continue working to find common ground among us and find shared foci or questions to navigate and determine our course in this extremely complex field of studies. The variety of contributions does indeed open up for the future, and provides clues regarding the new topics and discussions that need to be analysed and taken up under the title of Religion and Gender. At the very least, it gives us much to think about and chew on, and we are very curious and look forward to learn how Religion and Gender will look like in the year 2031!

\section{References}

Editors Religion and Gender. 2014. 'Editorial', Religion and Gender 4:2, 91-92.

Korte, Anne-Marie. 2011. 'Openings: A Genealogical Introduction to Religion and Gender', Religion and Gender 1:1, 1-17.

Schippert, Claudia. 2011. 'Implications of Queer Theory for the Study of Religion and Gender: Entering the Third Decade', Religion and Gender 1:1, 66-84.

Van Klinken and van den Brandt. 2019. 'Editorial', Religion and Gender 9:1, 1-5. 